Dedicated to Professor Romulus Cristescu on the occasion of his 90th birthday

\title{
The Abel-Steffensen inequality in higher dimensions
}

\section{CONSTANTin P. Niculescu}

\section{ABSTRACT.}

The Abel-Steffensen inequality is extended to the context of several variables. Applications to Fourier analysis and Riemann-Stieltjes integration are included.

\section{REFERENCES}

[1] Abel, N. H., Untersuchungen über die Reihe $1+\frac{m}{1} x+\frac{m(m-1)}{1 \cdot 2} x^{2}+\frac{m(m-1)(m-2)}{1 \cdot 2 \cdot 3} x^{3}+\cdots$, J. reine angew. Math., 1 (1826), 311-339. See also CEuvres complètes de N. H. Abel, t. I, pp. 66-92, Christiania, 1839

[2] Aksoy, A. and Martelli, M., Mixed partial derivatives and Fubini's theorem, College Math. J., 33 (2002), $126-130$

[3] Borwein, D. and Borwein, J. M., A Note on Alternating Series in Several Dimensions, Am. Math. Mon., 93 (1986), No. 7, 531-539

[4] Choudary, A. D. R. and Niculescu, C. P., Real Analysis on Intervals, Springer, 2014

[5] Hardy, G. H., On the Convergence of Certain Multiple Series Proc. London Math. Soc., 1 (1904), 124-128

[6] Hewitt, E. and Stromberg, K., Real and Abstract Analysis, Second printing corrected, Springer-Verlag, Berlin Heidelberg New York, 1969

[7] Nelsen, R. B., An Introduction to Copulas, 2nd ed., Springer, 2006

[8] Niculescu, C. P. and Persson, L.-E., Convex Functions and their Applications. A Contemporary Approach, Second edition, CMS Books in Mathematics, 23, Springer-Verlag, New York, 2018

[9] Niculescu, C. P. and Stănescu, M. M., The Steffensen-Popoviciu measures in the context of quasiconvex functions, J. Math. Inequal., 11 (2017), No. 2, 469-483

[10] Pečarić, J., Some Further Remarks on the Ostrowski Generalization of Čebyšev's Inequality, J. Math. Anal. Appl., 123 (1987), 18-33

[11] Rane, V. V., Analogues of Euler and Poisson summation formulae, Proc. Indian Acad. Sci. (Math. Sci.), 113 (2003), No. 3, 213-221

[12] Sklar, A., Random variables, distribution functions, and copulas - a personal look backward and forward. In: Rüschendorf, L., Schweizer, B. and Taylor, M. (eds), Distributions With Fixed Marginals \& Related Topics, IMS Lecture Notes - Monograph Series No. 28, 1996

[13] Šremr, J., Absolutely continuous functions of two variables in the sense of Carathéodory, Electronic Journal of Differential Equations (EJDE), 2010 (2010), No. 154, 1-11

[14] Steffensen, J. F., On certain inequalities and methods of approximation, J. Inst. Actuaries, 51 (1919), 274-297

[15] Willem, M, Analyse fonctionnelle élémentaire, Cassini, Paris, 2003

[16] Young, W. H., On multiple integrals, Proc. Roy. Soc. Series A, 93 (1917), No. 647, 28-41

ACADEMY OF ROMANIAN SCIENTISTS

SPLAIUL INDEPENDENŢEI 54

BUCHAREST 050085, ROMANIA

AND UNIVERSITY OF CRAIOVA, CRAIOVA, ROMANIA

Email address: cpniculescuegmail.com

Received: 08.08.2018; In revised form: 03.12.2018; Accepted: 10.12.2018

2010 Mathematics Subject Classification. 26D15, $26 \mathrm{~B} 25$.

Key words and phrases. Abel-Steffensen inequality, absolutely continuous function, convex function, $2 d-$ increasing function, Riemann-Stieltjes integral. 